Canadian Oncology

Nursing Journal

Revue canadienne

de soins infirmiers

en oncologie

Volume 28, Issue 2 • Spring 2018

elSSN: 2368-8076 


\title{
Empowering cancer survivors to meet their physical and psychosocial needs: An implementation evaluation
}

\author{
by Carrie M. Liska, Robin Morash, Lise Paquet, and Dawn Stacey
}

\begin{abstract}
Our Wellness Beyond Cancer Survivorship Program was established and evaluated as a quality improvement project. Individualized survivorship care plans for survivors and primary care providers included cancer surveillance recommendations and survivors' self-reported physical and psychosocial needs. At the discharge visit, an oncology nurse reviewed the care plan and symptom management strategies with survivors. We assessed the physical and psychosocial needs and feelings of empowerment of 70 breast and 53 colorectal cancer survivors on entry into the program and one year after discharge to primary care. Survivors were months to 10 or more years since the end of active treatment, with colorectal cancer survivors referred sooner (average 1.2 years). At baseline, colorectal cancer survivors reported little concern about their needs (scores $<1.0$ out of 5.0) and breast cancer survivors reported some concern about sleep disturbances, weight changes, memory/concentration changes, and fear of recurrence (scores 1.0 to 1.5 out of 5.0). All survivors reported feeling empowered ( $>3.0$ out of 4.0). Needs and empowerment levels were mostly unchanged one year later. Colorectal cancer survivors showed a statistically significantly increased fear of recurrence at one year. In summary, cancer survivors with a survivorship care plan continued to feel empowered one year following discharge.
\end{abstract}

Key words: cancer, survivorship, survivors, empowerment, primary care providers

\section{ABOUT THE AUTHORS}

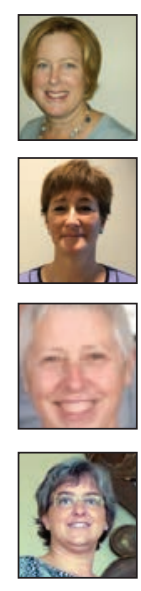

Carrie M. Liska, RN, MN, The Ottawa Hospital, Ottawa, ON

Robin Morash, RN, MHS, The Ottawa Hospital, Ottawa, ON

Lise Paquet, PhD, Carleton University, Ottawa, ON

Dawn Stacey, RN, PhD, University of Ottawa, Ottawa, ON

Address for correspondence: Carrie M. Liska, RN, MN, Care Facilitator, the Ottawa Hospital Cancer Program, 501 Smyth Road, Ottawa, ON K1H 8L6

Ph: 613-737-7700 Ext: 70264; Fax: 613-739-6965; Email: cliska@toh.on.ca

DOI:10.5737/236880762827681

\section{BACKGROUND}

$C$ ancer is now considered a chronic disease requiring the provision of high-quality, long-term, post-treatment care (Drayton et al., 2012; Phillips \& Currow, 2010). In 2016, 202,400 Canadians were diagnosed with cancer and, because of improvements in early detection and treatment, $60 \%$ are expected to survive their disease for five years or longer (Canadian Cancer Statistics, 2016). Consequently, long-term survivorship care is becoming a growing healthcare burden involving numerous resources such as psychosocial and supportive care, health promotion, late and long-term side-effects monitoring, follow-up surveillance, and screening detection of other cancers (Canadian Cancer Statistics, 2016; Howell et al., 2011; McCorkle, 2011; Morgan, 2009). As a result, there has been an increasing trend toward the utilization of community-based models of survivorship care led by primary care providers (Dawes et al, 2015). Unfortunately, little is known about patients' psychosocial needs once their care has been transitioned to primary care (Hebdon et al., 2014; Lewis et al., 2009).

One important psychosocial outcome of cancer survivorship care is patient empowerment (Jerofke, 2013; McCorkle, 2011; Kuijpers, 2013; Lauzier et al., 2014; van den Berg et al., 2013). Empowerment is felt to be an attitude that some patients possess by being more involved in the treatment of their illness and an empowered patient proactively seeks solutions by asking questions for themselves to manage their illness (Bulsara, Stiles, Ward, \& Bulsara, 2006; Bulsara \& Styles, 2013). Empowering patients with a chronic illness such as cancer is crucial to assist them address and cope with their disease and decrease psychological distress (Bulsara, Stiles, Ward, \& Bulsara, 2006). According to the Chronic Care Model (Wagner, 2001) self-management support is provided to empower and prepare patients to manage their healthcare. Self-management strategies by health care providers include educational and supportive interventions to enhance patient's skills and confidence to manage their health concerns (Adams, Greiner, \& Corrigan, 2004; McCorkle, 2011).

Unfortunately, research on empowerment during post-treatment cancer survivorship care is scarce and has relied on indirect measures of empowerment such as, nurses' perception of empowerment (Mok, Martinson, \& Wong, 2004; van Uden-Kraan et al., 2008), or the assessment of related concepts such as quality of life, anxiety, symptom management, increased knowledge and coping skills (Ryhänen et al., 2013; Kane, Boland, \& Herst, 2014; Pereira, 2014; Jerofke, 2013; Knobf, 2013; McCarley, 2009; Morgan, 2009), rather than using a more direct measure of cancer survivors' perspectives (McAllister et al., 2012). Therefore, little is known about whether programs focusing on discharging cancer survivors 
for follow-up in primary care adequately empower patients to proactively ask questions and seek solutions for themselves to manage their needs during the survivorship phase of the cancer trajectory (Bulsara \& Styles, 2013).

In 2006, the Institute for Medicine's From Cancer Patient to Cancer Survivor: Lost in Transition report made four recommendations for survivorship care: (a) prevention strategies for late effects, including recurrence; (b) provide surveillance for cancer spread; (c) interventions for consequences of cancer and its treatment; and (d) coordinate care between specialists and primary care providers.

Cancer centres have been tasked to integrate those four key components of survivorship care. As well, Canadian Accreditation Standards require effective communication between health care providers when transferring patient care to prevent misunderstandings and, more specifically, expect patients and families to receive high-quality, evidence-based and standardized information for making decisions and supporting their care (Accreditation Canada \& Health Standards Organization, 2017). Recognizing the need to integrate survivorship care to meet the unique needs of survivors, and heeding the recommendations of the Institute of Medicine (2006) and surveillance guidelines of Cancer Care Ontario (2012), the Wellness Beyond Cancer Program (WBCP) at The Ottawa Hospital Cancer Centre was developed to provide high-quality survivorship care to those at the end of their active treatment. The WBCP was launched in March 2012 for colorectal and endometrial cancer survivors and in February 2013 for breast cancer survivors.

\section{PURPOSE}

The purpose of this project was to describe the physical and psychosocial needs of colorectal and breast cancer survivors and their feelings of empowerment on entry into the WBCP and one year after transitioning to primary care. Specific objectives were to determine: (a) changes in self-identified physical and psychosocial needs one year after transitioning to primary care, (b) changes in feelings of empowerment one year after transitioning to primary care; and (c) if any changes over time were observed; whether changes in feelings of empowerment were linked to changes in physical and psychosocial needs.

\section{METHODS}

A quality improvement (QI) project was conducted with patients referred to the WBCP between March 2012 and June 2013. QI projects often originate from discussions amongst clinicians and aim to assess clinical practices to determine the need for practice change (Polit \& Beck, 2012). The QI project was reviewed by the Chairman of The Ottawa Health Science Network Research Ethics Board (REB) who agreed that it was a QI project and did not require REB approval.

\section{Study Setting}

The WBCP is an ambulatory oncology cancer survivorship program at a large academic teaching hospital serving a population of 1.3 million people in Eastern Ontario. Patients being transferred to primary care are referred by oncologists at the end of their active treatment, when there is stability of symptoms without ongoing medical concerns and the risk of relapse is considered to be low. The WBCP was designed based on the Supportive Care Framework (Fitch, 2008) and the principles of the Chronic Care Model (Wagner, 2001). The program purpose is to ensure that patients at the end of their active treatment have access to resources and support: (a) to meet their outstanding physical and psychosocial needs, and (b) to feel empowered to participate with their primary care provider in the management of their follow-up care.

\section{Study Participants}

When the program was launched, many cancer survivors who had been followed for many years at the cancer centre were encouraged to transition through the WBCP to have their follow-up monitoring care transferred to their primary care provider. Eligible patients had colorectal cancer or breast cancer, completed their active cancer treatment, and were at low risk of recurrence.

\section{PROCEDURES}

Patients referred to the WBCP are routinely asked to complete a physical and psychosocial needs assessment and the Bulsara et al. (2006) patient empowerment scale survey. Patients are then routinely provided with four key interventions while part of the WBCP.

First, patients are invited to attend a two-hour, disease-specific, evidence-based didactic education class. Education topics include the coordination of care at the time of discharge, screening for other cancers, healthy lifestyle behaviours, symptom management of the most common late and long-term physical and psychosocial effects due to cancer treatment, and the process to re-enter the cancer program in the future, if required.

Second, at the education class patients receive disease-specific printed materials and access to available web-based resources on common late and long-term effects. Third, an individualized survivorship care plan is prepared by an oncology nurse that outlines the patient's cancer care team, disease and treatment summary, and follow-up surveillance guidelines. Patients' self-identified physical and psychosocial needs that are indicated as being moderate to extreme on the needs assessment are included in the care plan.

Fourth, all patients are invited to attend a 30-minute discharge visit and care plan review with an oncology nurse. A copy of the care plan is reviewed and provided to the patient and the nurse discusses symptom management strategies to address any outstanding self-identified physical and psychosocial needs. A dictated note of the discharge visit, discharge letter, and copy of the care plan are sent to the patient's primary care provider. The WBCP phone number is also provided to the primary care provider to address potential future questions/concerns and to ensure an expedited re-entry to the cancer program, if necessary.

For the QI project only, the needs assessment and patient empowerment scale survey were mailed to the patient one year after the date of referral to the WBCP and they were invited to complete and return the survey. 


\section{Data Collection Tools}

The data collection tools were chosen based on the Supportive Care Framework (Fitch, 2008) and the Chronic Care Model (Wagner, 2001). The needs assessment survey was adapted from the Cancer Survivors Survey of Needs with verbal permission from the Mayo Clinic Cancer Education Program (Mayo Clinic Cancer Center, n.d.). The survey has 50 items used to rate physical and psychosocial symptoms on a six-point Likert scale, with 0 indicating no concerns and 5 indicating extreme concerns. This tool was used to identify physical and psychosocial supportive care needs. For the purpose of this study, we focused only on the nine key physical and psychosocial needs that were being reported by WBCP patients and known to be most problematic for cancer survivors of breast and colorectal cancer (Rushton et al., 2015; Schlairet, Heddon, \& Griffis, 2010).

The cancer-specific Bulsara Patient Empowerment Scale consists of 15 statements rated on a four-point Likert scale from strongly agree to strongly disagree (Bulsara et al., 2006). Higher scores indicated higher feelings of empowerment. The Cronbach's alpha for the empowerment scale was 0.85 at baseline and 0.90 at follow-up, indicating very good internal consistency reliability. Principal components analysis indicated that the items selected had similar factor loadings > .66.

\section{Analysis}

All data from the physical and psychosocial needs assessment and empowerment scale were entered into SPSS. The colorectal cancer and breast cancer survivors' findings were analyzed separately using the same methods. As a first step,

\begin{tabular}{|c|c|c|}
\hline \multicolumn{3}{|c|}{ Table 1: Characteristics of participants } \\
\hline Item & Colorectal $\mathrm{N}=53$ & Breast $\mathrm{N}=70$ \\
\hline Age Range (range) & $38-90$ & $42-92$ \\
\hline$<49$ years & 2 & 7 \\
\hline $50-59$ & 8 & 18 \\
\hline $60-69$ & 12 & 19 \\
\hline $70-79$ & 20 & 17 \\
\hline$>80$ & 11 & 9 \\
\hline \multicolumn{3}{|l|}{ Sex: } \\
\hline Male & 35 & 0 \\
\hline Female & 18 & 70 \\
\hline \multicolumn{3}{|l|}{ Marital Status: } \\
\hline Married/Cohabitating & 37 & 43 \\
\hline Not Married/Widowed & 16 & 17 \\
\hline $\begin{array}{l}\text { Time from Treatment } \\
\text { (range) }\end{array}$ & 1 Month to 10 Years & 2-17 Years \\
\hline$<1$ year & 35 & 13 \\
\hline $1-2$ years & 8 & 7 \\
\hline$>2-3$ years & 5 & 7 \\
\hline$>3-5$ years & 3 & 13 \\
\hline$>5-10$ years & 1 & 25 \\
\hline$>10$ years & 1 & 5 \\
\hline
\end{tabular}

dependent T-tests were used to measure changes in needs and empowerment over time. If required following completion of the first step analyses, correlation analyses would be conducted to examine whether changes in empowerment were linked to changes in needs correlation.

\section{RESULTS}

The breast and colorectal cancer survivors had a similar range of ages and marital status. CRC survivors' time from the end of active treatment averaged 1.2 years (range 1 month to 10 years) since completing active treatment. The breast cancer survivors averaged 4.6 years (range 2 years to 17 years) since their last active treatment (see Table 1).

\section{Colorectal Cancer Survivor Results}

Of 131 CRC survivors referred to the WBCP between March and September 2012, 126 completed the baseline assessment (96\% response rate). At one year post, 125 CRC survivors were sent the questionnaire and 53 returned them completed (42\% response rate). At baseline, colorectal cancer survivors reported little concern about their needs (scores $<1.0$ out of 5.0 ) and felt empowered (3.00 to 3.76 out of 4.0 ) (see Tables 2-3).

\begin{tabular}{|c|c|c|c|}
\hline \multicolumn{4}{|c|}{$\begin{array}{l}\text { Table 2: Survivors' concerns about th } \\
\text { needs }\end{array}$} \\
\hline \multicolumn{4}{|c|}{ A: Colorectal cancer group $(\mathrm{N}=53)$} \\
\hline \multirow[t]{2}{*}{ Domain } & Baseline & 1 year post & \multirow[t]{2}{*}{ p value } \\
\hline & Mean (SD) & Mean (SD) & \\
\hline Tingling in hands/feet & $0.79(1.32)$ & $0.88(1.35)$ & 0.647 \\
\hline Sexual Issue & $0.87(1.29)$ & $0.83(1.31)$ & 0.796 \\
\hline Sleep Disturbances & $0.88(1.26)$ & $0.74(1.03)$ & 0.398 \\
\hline Bowel/bladder issues & $0.94(1.51)$ & $1.04(1.38)$ & 0.601 \\
\hline Fatigue & $0.86(1.02)$ & $1.00(1.06)$ & 0.332 \\
\hline Weight changes & $0.86(1.34)$ & $0.65(1.02)$ & 0.201 \\
\hline Body changes & $0.79(1.18)$ & $0.83(1.11)$ & 0.761 \\
\hline $\begin{array}{l}\text { Memory and } \\
\text { concentration }\end{array}$ & $0.73(1.22)$ & $0.76(1.64)$ & 0.883 \\
\hline Fear of Recurrence & $0.79(1.24)$ & $1.31(1.20)$ & 0.005 \\
\hline \multicolumn{4}{|c|}{ B: Breast cancer patients $(\mathrm{N}=70)$} \\
\hline \multirow[t]{2}{*}{ Domain } & Baseline & 1 year post & \multirow[t]{2}{*}{ p value } \\
\hline & Mean (SD) & Mean (SD) & \\
\hline Tingling in hands/feet & $0.71(1.17)$ & $0.92(1.37)$ & 0.262 \\
\hline Sexual Issue & $0.78(1.34)$ & $0.97(1.44)$ & 0.077 \\
\hline Sleep Disturbances & $1.00(1.19)$ & $1.23(1.42)$ & 0.148 \\
\hline Bowel/bladder issues & $0.68(0.97)$ & $0.83(1.11)$ & 0.335 \\
\hline Fatigue & $0.98(1.20)$ & $1.16(1.36)$ & 0.181 \\
\hline Weight changes & $1.10(1.38)$ & $0.93(1.31)$ & 0.531 \\
\hline Body changes & $0.85(1.19)$ & $1.06(1.29)$ & 0.180 \\
\hline $\begin{array}{l}\text { Memory and } \\
\text { concentration }\end{array}$ & $1.08(1.16)$ & $1.16(1.36)$ & 0.608 \\
\hline Fear of Recurrence & $1.46(1.48)$ & $1.50(1.41)$ & 0.775 \\
\hline
\end{tabular}


Over time, there was no overall statistically significant change in eight of the nine self-reported physical and psychosocial needs for the colorectal cancer survivors. Their fear of recurrence increased, however, from 0.79 to 1.31 out of 5.0 $(\mathrm{p}=0.005)$ (see Table 2$)$.

There were no statistically significant changes in empowerment over time for the colorectal cancer survivors (see Table 3). Consequently, correlation analyses were not conducted.

\section{Breast Cancer Survivor Results}

Of 164 breast cancer survivors referred to the WBCP between January 2013 and June 2013, 163 completed the baseline assessment ( $99 \%$ response rate). At one year post, 163 breast cancer survivors were sent the questionnaire and 70 returned them completed ( $43 \%$ response rate). At baseline, breast cancer survivors reported some concern about sleep disturbances, weight changes, memory/concentration, and fear of recurrence (1.00 to 1.46 out of 5.0) and felt empowered (3.06 to 3.75 out of 4.0 ) (see Tables 2-3).

There were no statistically significant changes over time in the needs of the breast cancer survivors and no changes in empowerment occurred over time (see Tables 2-3). Consequently, correlation analyses were not conducted.

\begin{tabular}{|c|c|c|c|}
\hline \multicolumn{4}{|l|}{ A: Colorectal cancer patients $(\mathrm{N}=53)$} \\
\hline \multirow[t]{2}{*}{ Domain } & Baseline & 1 Year post & \multirow[t]{2}{*}{ p value } \\
\hline & Mean (SD) & Mean (SD) & \\
\hline I am capable of handling my illness & $3.64(0.486)$ & $3.49(0.547)$ & 0.070 \\
\hline I have all the information I need to manage my illness & $3.42(0.753)$ & $3.33(0.674)$ & 0.420 \\
\hline I am capable of helping health professionals reach decisions related to my illness & $3.57(0.547)$ & $3.50(0.552)$ & 0.412 \\
\hline My family are very supportive & $3.76(0.480)$ & $3.63(0.610)$ & 0.204 \\
\hline I need the support of my family and friends & $3.45(0.730)$ & $3.25(0.719)$ & 0.095 \\
\hline My family and friends still rely on me & $3.30(0.765)$ & $3.07(0.873)$ & 0.086 \\
\hline I can adapt to the changes in my lifestyle & $3.51(0.626)$ & $3.38(0.614)$ & 0.183 \\
\hline Health professionals are happy to include me in decisions related to my illness & $3.66(0.481)$ & $3.50(0.558)$ & 0.136 \\
\hline I want my family and friends to continue to rely on me & $3.24(0.773)$ & $3.20(0.919)$ & 0.710 \\
\hline My friends are always supportive & $3.50(0.619)$ & $3.40(0.707)$ & 0.341 \\
\hline I still feel useful in my daily life & $3.51(0.585)$ & $3.45(0.583)$ & 0.519 \\
\hline My spiritual beliefs help me cope with my illness & $3.29(0.782)$ & $3.37(0.799)$ & 0.519 \\
\hline I accept that I have to change my lifestyle & $3.20(0.687)$ & $3.23(0.620)$ & 0.850 \\
\hline Complementary therapies help me cope with my illness & $3.00(0.791)$ & $3.18(0.809)$ & 0.422 \\
\hline I have a lot of confidence in my local family physician & $3.60(0.681)$ & $3.70(0.507)$ & 0.280 \\
\hline \multicolumn{4}{|l|}{ B: Breast cancer patients $(\mathrm{N}=70)$} \\
\hline \multirow[t]{2}{*}{ Domain } & Baseline & 1 year post & \multirow[t]{2}{*}{ p value } \\
\hline & Mean (SD) & Mean (SD) & \\
\hline I am capable of handling my illness & $3.46(0.534)$ & $3.56(0.501)$ & 0.159 \\
\hline I have all the information I need to manage my illness & $3.49(0.592)$ & $3.44(0.562)$ & 0.536 \\
\hline I am capable of helping health professionals reach decisions related to my illness & $3.53(0.566)$ & $3.55(0.565)$ & 0.843 \\
\hline My family are very supportive & $3.75(0.434)$ & $3.70(0.460)$ & 0.471 \\
\hline I need the support of my family and friends & $3.50(0.505)$ & $3.55(0.537)$ & 0.518 \\
\hline My family and friends still rely on me & $3.35(0.641)$ & $3.39(0.559)$ & 0.699 \\
\hline I can adapt to the changes in my lifestyle & $3.54(0.503)$ & $3.46(0.537)$ & 0.301 \\
\hline Health professionals are happy to include me in decisions related to my illness & $3.52(0.504)$ & $3.54(0.539)$ & 0.821 \\
\hline I want my family and friends to continue to rely on me & $3.35(0.645)$ & $3.38(0.593)$ & 0.687 \\
\hline My friends are always supportive & $3.54(0.502)$ & $3.51(0.536)$ & 0.621 \\
\hline I still feel useful in my daily life & $3.62(0.522)$ & $3.49(0.595)$ & 0.059 \\
\hline My spiritual beliefs help me cope with my illness & $3.29(0.733)$ & $3.29(0.731)$ & 1.00 \\
\hline I accept that I have to change my lifestyle & $3.13(0.672)$ & $3.19(0.704)$ & 0.652 \\
\hline Complementary therapies help me cope with my illness & $3.06(0.854)$ & $2.94(0.814)$ & 0.489 \\
\hline I have a lot of confidence in my local family physician & $3.46(0.727)$ & $3.47(0.796)$ & 0.811 \\
\hline
\end{tabular}




\section{DISCUSSION}

This QI project described low levels of physical and psychosocial needs of colorectal cancer and breast cancer survivors and their high feelings of empowerment on entry into the WBCP program. The overall self-reported physical and psychosocial needs and empowerment levels of these cancer survivors showed mostly no statistically significant changes one year after discharge from a cancer centre back to their primary care provider. Only the colorectal survivors showed an increased fear of cancer recurrence at one year, as one of the key psychosocial needs. It is unclear why this group felt an increase in fear of cancer recurrence but, interestingly, they were also referred to the WBCP sooner after completing their active treatment (average 1.2 years) compared to the breast cancer group (average 4.6 years). Our findings lead us to discuss three important issues for improving care for cancer survivors.

First, defining patient empowerment in the context of cancer survivorship may provide clarity and a foundation to those caring for cancer survivors. An analysis of 67 articles defining patient empowerment revealed definitions focusing on: (a) a transformative process, as patients gain control of their health and healthcare to adapt to a chronic illness; (b) principles indicating a state of autonomy and self-determination; and/or (c) interventions for self-management of chronic illness (Bravo, Edwards, Barr, Scholl, Elwyn, \& McAllister, 2015). Patient outcomes based on these definitions were adaptation to a chronic illness, quality of life, well-being, satisfaction with life, and independence. Research has demonstrated that interventions engaging patients and supporting patient empowerment provide for greater patient satisfaction, better health, and lower costs and empowering cancer survivors is now being emphasized as essential (Eskildsen et. al., 2017).

Second, discharging low-risk cancer patients to their primary care provider has previously been shown to be safe, cost effective, and is often preferred by patients (Grant, De Rossi, \& Sussman, 2015). However, primary care providers report lacking knowledge, confidence, and resources such as printed guidelines (Dawes et. al., 2015; Luctkar-Flude, Aiken, McColl, \& Tramner, 2015). Opportunities exist to improve their knowledge on evidence-based practice guidelines, limiting unnecessary tests, and improving the coordination of care between oncology specialists and primary care providers (Grant, De Rossi, \& Sussman, 2015; Luctkar-Flude, et al., 2015). In this study, the survivorship care plan provided by the WBCP to cancer survivors and their primary care provider was designed to provide a treatment summary, evidence-based guidance on follow-up surveillance tests, communicate patients' self-identified physical and psychosocial needs, and provide guidance on symptom management strategies tailored to cancer survivors' individual physical and psychosocial needs. Concurrently with guidance to primary care providers, the survivorship care plan was used to increase cancer

\section{REFERENCES}

Accreditation Canada and Health Standards Organization. Required organizational practices handbook 2017. Ottawa.

Adams, K., Greiner, A.C., \& Corrigan, J. M. (2004). Report of a summit. The 1st annual crossing the quality chasm summit: A focus on communities. Washington, DC: National Academies Press.

Bravo, P., Edwards, A., Barr, P.J., Scholl, I., Elwyn, G., \& McAllister, M. (2015). Conceptualising patient empowerment: A mixed methods study. BMC Health Services Research, 15(1), 252. survivors' understanding of the follow-up care that is required and empower them to actively participate in the management of their care (Dawes, et al., 2014; Grant, De Rossi, \& Sussman, 2015; Jabson, 2014; Luctkar-Flude et al., 2015; McCorkle, 2011).

Third, although the literature supports education to empowering survivors, there is little evidence supporting specific interventions. Online support groups, web-based interventions, and education classes have been shown to effectively empower cancer patients and patients with other chronic diseases (Kuijpers et al., 2013; Pereira, 2014; van Uden-Kraan et al., 2008). Hence, the WBCP could continue providing education classes and consider more rigorous evaluation to verify their effectiveness for this specific patient population and, in particular, for those soon after they have completed active treatment.

\section{LIMITATIONS}

There are three key limitations to consider. First, the sample sizes for both the colorectal cancer and breast cancer survivors were too small to draw strong conclusions. Second, a wide variance in the range of time between the end of active treatment and referral to the program existed amongst participants. This wide variance is felt to impact participants' self-reported outstanding physical and psychosocial needs and likely influenced their feelings of empowerment. Third, research is required on each of the four key interventions utilized by the WBCP to determine their unique effectiveness.

\section{CONCLUSION}

Cancer survivorship as a chronic illness is a new perspective and few empowerment interventions have been developed or used. The WBCP was established to prepare cancer survivors for discharge of their follow-up care from their oncologist to their primary care provider. Four key interventions routinely used in this program include an education class, printed patient education materials, an individualized survivorship care plan tailored to patients' unique physical and psychosocial needs, and an oncology nurse-led discharge visit with a care plan review. Through monitoring their needs and feelings of empowerment at baseline and one year after discharge for this QI project, however, we found mostly no statistically significant changes in their physical and psychosocial needs or changes in their feelings of empowerment for both colorectal and breast cancer survivors post one year. Colorectal cancer survivors showed a statistically significant increase in fear of recurrence at one year. Oncology nurses are well-positioned to recognize the unique needs of cancer survivors and facilitate ways to support meeting their needs by providing educational sessions and individualized survivorship care plans and helping them feel empowered to manage their chronic disease, as they transition to primary care. Future research is needed to explore the contribution of educational sessions and individualized survivorship care plans.

Bulsara, C.E., \& Styles, I. (2013). Development of a cancer related patient empowerment scale using the polytomous Rasch measurement model. Cancer and Clinical Oncology, 2(1), 87.

Bulsara, C., Styles, I., Ward, A.M., \& Bulsara, M. (2006). The psychometrics of developing the patient empowerment scale. Journal of Psychosocial Oncology, 24(2), 1-16.

Canadian Cancer Statistics (2016). Canadian Cancer Society, Statistics Canada. Government of Canada. Retrieved from http://www. 
cancer.ca/ /media/cancer.ca/CW/cancer\%20information/ cancer\%20101/Canadian\%20cancer\%20statistics/CanadianCancer-Statistics-2016-EN.pdf?la=en

Cancer Care Ontario Members of the Colorectal Cancer Survivorship Group (2012). Follow-up care, surveillance protocol, and secondary prevention measures for survivors of colorectal cancer. Toronto (ON): Cancer Care Ontario; 2012 Feb 3. Program in Evidence-based Care Evidence-Based Series No.: 26-2 Version 2

Dawes, A.J., Hemmelgarn, M., Nguyen, D.K., Sacks, G.D., Clayton, S.M., Cope, J.R., Maggard-Gibbons, M. (2015). Are primary care providers prepared to care for survivors of breast cancer in the safety net? Cancer, 121(8), 1249-1256.

Drayton, M., Tamblyn, M., Mercer, C., Ontario Agency for Health Protection and Promotion, Public Health Ontario, Cancer Care Ontario. Canadian Electronic Library (Firm). (2012). Taking action to prevent chronic disease: Recommendations for a healthier Ontario. Toronto, ON: Ontario Agency for Health Protection and Promotion.

Eskildsen, N.B., Joergensen, C.R., Thomsen, T.G., Ross, L., Dietz, S.M., Groenvold, M., \& Johnsen, A.T. (2017). Patient empowerment: A systematic review of questionnaires measuring empowerment in cancer patients. Acta oncologica (Stockholm, Sweden), 56(2), 156.

Fitch, M.I. (2008). Supportive care framework. Canadian Oncology Nursing Journal/Revue canadienne de soins infirmiers en oncologie, 18(1), 6-14.doi:10.5737/1181912x181614

Grant, M., De Rossi, S., Sussman, J. (2015). Supporting models to transition breast cancer survivors to primary care: Formative evaluation of a cancer care Ontario initiative. American Society of Clinical Oncology. doi:10.1200/JOP.2015.003822

Hebdon, M., Abrahamson, K., McComb, S., \& Sands, L. (2014). Transitioning patients to survivorship care: A systematic review. Oncology Nursing Forum, 41(6), 615-625.

Howell, D., Hack, T., Oliver, T.K., Chulak, T. Mayo, S., Aubin, M., Chasen, M., ... Tompson, M. (2011). Survivorship services for adult cancer populations: A pan-canadian guideline. Current Oncology, 18(6), 265-281.

Institute of Medicine and National Research Council (2006). From Cancer Patient to Cancer Survivor: Lost in Transition. Washington, D.C: The National Academies Press. Washington D.C.

Jabson, J. (2014). Follow-up care instructions, treatment summaries, and cancer survivors' receipt of follow-up health care and late/long term effects. Support Care Cancer. doi:10.1007/s00520-014-2532-5

Jerofke, T.A. (2013). Concept analysis of empowerment from survivor and nurse perspectives within the context of cancer survivorship. Research and Theory for Nursing Practice: An International Journal, 27(3), 157-172. doi.org:/10.1891/1541-6577.27.3.157

Kane, P., Boland, P., \& Herst, P. (2014). A pathway to empowerment: Evaluating a cancer education and support programme in New Zealand. European Journal of Cancer Care, 23(5), 668-674. doi: 10.1111/ecc.12188

Knobf, T. (2013). Being prepared: Essential to self-care and quality of life for the person with cancer. Clinical Journal of Oncology Nursing, 17(3). doi:10:1188/13.CJON.255-261

Kuijpers, W., Groen, W.G., Aaronson, N.K., \& van Harten, W.H. (2013). A systematic review of web-based interventions for patient empowerment and physical activity in chronic diseases: relevance for cancer survivors. Journal of Medical Internet Research, 15(2).

Lauzier, S., Campbell, H.S., Livingston, P.M., \& Maunsell, E. (2014). Indicators for evaluating cancer organizations' support services: Performance and associations with empowerment. Cancer, 120(20), 3219-3227. doi:10.1002/cncr.28846
Lewis, R.A., Neal, R.D., Williams, N.H., France, B., Hendry, M., Russell, D., \& Wilkinson, C. (2009). Follow-up of cancer in primary care versus secondary care: Systematic review. British Journal of General Practice, 59(564), e234-e247.

Luctkar-Flude, M., Aiken, A., McColl, M.A., \& Tramner, J. (2015). A comprehensive framework and key guideline recommendations for the provision of evidence-based breast cancer survivorship care within the primary care setting. Family Practice, 32(2). 129-140. doi:10.1093/fampra/cmu082

Mayo Clinic Cancer Center (N.D.). Cancer Survivors Survey of Needs. Unpublished instrument, Cancer Education Program of the Mayo Clinic Cancer Center, Rochester, MN.

McAllister, M., Dunn, G., Payne, K., Davies, L., \& Todd, C. (2012). Patient empowerment: The need to consider it as a measurable patient-reported outcome for chronic conditions. BMC Health Services Research, 12(1), 157.

McCarley, P. (2009). Patient empowerment and motivational interviewing: Engaging patients to self-manage their own care. Nephrology Nursing Journal, 36(4), 409-413.

McCorkle, R., Ercolano, E., Lazenby, M., Schulman-Green, D., Schilling, L.S., Lorig, K., \& Wagner, E.H. (2011). Self-management: Enabling and empowering patients living with cancer as a chronic illness. CA: American Cancer Journal for Clinicians, 61, 50-62. doi:10.3322//caac. 20093

Mok, E., Martinson, I., \& Wong, T.K. (2004). Individual empowerment among Chinese cancer patients in Hong Kong. Western Journal of Nursing Research, 26(1), 59-75.

Morgan, M.A. (2009). Cancer survivorship: History, quality-oflife issues, and the evolving multidisciplinary approach to implementation of cancer survivorship care plans. Oncology Nursing Forum, 36(4), 429-436.

Pereira, N. (2014). Educating and empowering colorectal cancer survivors. Gastrointestinal Nursing, 12(9), 33-40.

Phillips, J.L., \& Currow, D.C. (2010). Cancer as a chronic disease. Collegian, 17(2), 47-50.

Polit, D.B., \& Beck, T.C. (2012). Nursing research. Generating and assessing evidence for nursing practice (9th ed.). Philadelphia, PA. Wolters Kluwer. Lippincott Williams \& Wilkins.

Rushton, M., Morash, R., Larocque, G., Liska, C., Stocia, L., DeGrasse, C., \& Segal, R. (2015). Wellness beyond cancer program: Building an effective survivorship program. Current Oncology, 22(6), 419434. https://doi.org/10.3747/co.22.2786

Ryhanen, A.M., Rankinen, S. Siekkinen, M. Saarinen, M., Korvenranta, H., \& Leino-Kilpi, H. (2013). The impact of an empowering internet-based breast cancer patient pathway on breast cancer patients' clinical outcomes: A randomized controlled trial. Journal of Clinical Nursing, 22(7-8), 1016-1025.

Schlairet, M., Heddon, M.A., \& Griffis, M. (2010). Piloting a needs assessment to guide development of a survivorship program for a community cancer center. Oncology Nursing Forum, 37(4), 501-508.

van den Berg, S.W., Van Amstel, F.K.P., Ottevanger, P.B., Gielissen, M.F.M., \& Prins, J.B. (2013). The cancer empowerment questionnaire: Psychological empowerment in breast cancer survivors. Journal of Psychosocial Oncology, 31(5), 565-583. doi:10.10 80/07347332.2013.825361

van Uden-Kraan, C.F., Drossaert, C.H., Taal, E., Shaw, B.R., Seydel, E.R., \& van de Laar, M.A. (2008). Empowering processes and outcomes of participation in online support groups for patients with breast cancer, arthritis, or fibromyalgia. Qualitative Health Research, 18(3), 405-417.

Wagner, E.H., Austin, B.T., Davis, C., Hindmarsh, M., Schaefer, J., \& Bonomi, A. (2001). Improving chronic illness care: Translating evidence into action. Health Affairs, 20(6), 64-78. 